\title{
XXXIX. A duplex mercurial air-pump
}

\section{R. W. Wood}

To cite this article: R. W. Wood (1896) XXXIX. A duplex mercurial air-pump, Philosophical Magazine Series 5, 41:251, 378-381, DOI: 10.1080/14786449608620854

To link to this article: http://dx.doi.org/10.1080/14786449608620854

$$
\text { 曲 Published online: } 08 \text { May } 2009 .
$$

Submit your article to this journal 준

Џll Article views: 2

Q View related articles $\asymp$ 
angle $\theta$ may be laid off. The modulus of the cell is best changed by varying either A or B. This may be conveniently done by making each of either the long pair or the short pair of links like the legs of a pair of proportional dividers.

A small model of an instrument on the above lines has been constructed and found to work very easily and accurately. Like all hyperbolagraphs, however, the range of motion is limited (although larger in this than in most forms), and a considerable amount of time is necessary for the preliminary adjustment. For these reasons I have generally found one of the preceding graphical solutions more rapid and convenient, especially when a number of curves are to be drawn on the same sheet.

This application of the quadruplane, which occurred to me recently while making an application of the Peaucellier linkage to a concave grating mounting *, seems so simple and obvious that I feel sure it must have occurred to others as well as myself; but as I have not been able to find any suggestion to this effect in any of the papers on the subject that I have examined, I have ventured to present the foregoing description as another illustration of the practical application of the beautiful geometrical discovery of Prof. Sylvester and Mr. Kempe.

Ryerson Physical Laboratory,

University of Chicago, U.S.A., January 1896.

XXXIX. A Duplex Mercurial Air-Pump.

$B y$ R. W. Woon †.

TN working with highly exhausted tubes, such as are used 1 for the production of the Röntgen rays, one of the difficuities met with is the speedy deterioration of the vacuum due to the liberation of gas from the electrodes and the glass. If the tube be thoroughly heated, while on the air-pump, this trouble is partially remedied, but even with this precaution the tubes are not very durable and have to be pumped out frequently. In order to overcome this difficulty $I$ have constructed a new form of mercurial air-pump, which can be made on a very small scale and attached permanently to the Röntgen tube. By this arrangement, any traces of gas that

* "On the Use and Mounting of the Concave Grating as an Analyzing or Direct Comparison Spectroscope," The Astro-Physical Journal,' vol. iii. p. 47 (Jan. 1896).

+ Communicated by the Author. 
make their appearance can be easily pumped out. The apparatus is so compact that it can be held in the hands while in operation, not requiring mounting on a board. The pump is very simple, and a glance at the accompanying diagrams will make its construction clear. It will be seen to consist of

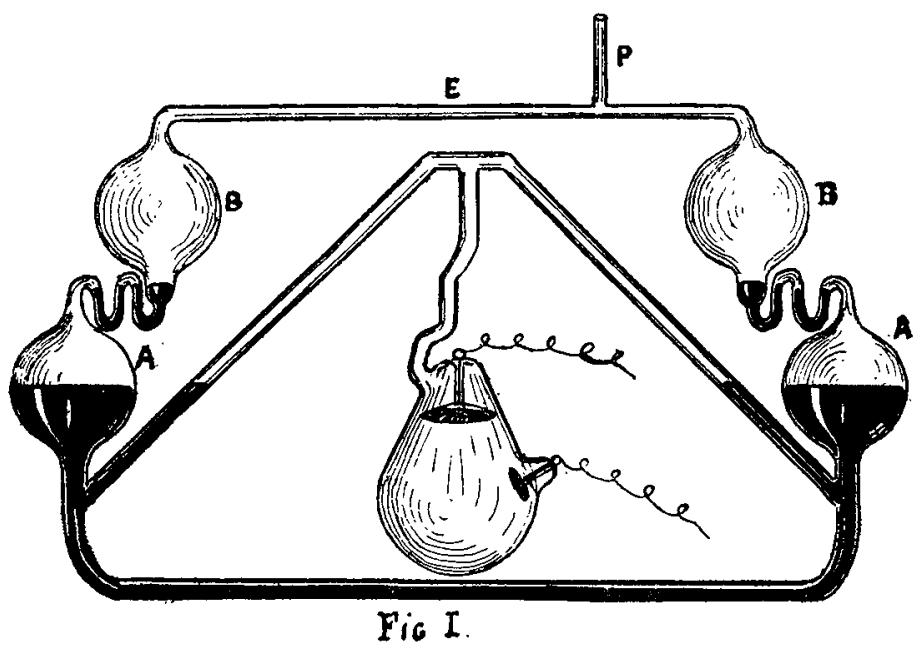

two bulb-pumps joined at the base by a $U$-tube of glass (fig. 1 ). The pumping is done by rocking the apparatus, the mercury filling the exhaust-bulbs A A alternately. This duplex action makes the pumping very rapid, for one bulb exhausts while the other fills, there being no lost time. The traces of gas liberated in the discharge-tube are pumped over into the exhausted bulbs B B, where they are stored, being prevented from returning by the mercury which remains in the $W$ traps between $A$ and $B$. The upper bulbs are joined by a tube $E$, which has a small lateral tube $\mathrm{P}$ blown into it ; this arrangement being necessary for the preliminary exhaustion.

Mercury is first introduced through P until the bulbs A A are half full. A gentle rocking of the apparatus is necessary, as the fluid is held up in the bulbs $B$ by the compression of the air in A.

When enough mereury has been introduced, the apparatus is placed in the position shown in fig. 3 , when the fluid should stand at the level indicated in the diagram. The side tube $P$ is now drawn out into a thick-walled capillary in a blast-lamp, in order to facilitate the subsequent closing of the apparatus. This tube being connected with a good mercurypump by means of a well-greased, thick-walled rubber hose, 


\section{Mr. R. W. Wood on a Duplex Mercurial Air-Pump.}

the apparatus is exhausted as completely as possible. During the exhaustion it must be supported in the position shown in fig. 3 ; otherwise the air escaping from the discharge-tube will throw the mercury violently against the top of the bulbs. It is a good plan to carefully heat the bulbs and the dischargetube by means of a Bunsen burner while the pump is in action, in order to drive off moisture. The current of a fairsized induction-coil should also be passed through the discharge-tube for a few minutes to rid the electrodes of air as completely as possible. It will be found that the vacuum cannot be made perfect enough to give a Crookes dark space of more than an inch, owing to the leakage through the rubber hose. The capillary part of $\mathrm{P}$ is now heated to fusion in a small flame which hermetically seals the entire apparatus. The comparatively poor vacuum in the discharge-tube can now be made as perfect as is possible with any mercury-pump by slowly rocking the apparatus, holding it by the bulbs A A. If the pump is properly made, the traps hold and require no attention : if not, a little dexterity is required, to prevent the mercury from running out into the bulb, and they have to be constantly watched. Care must of course be taken that the
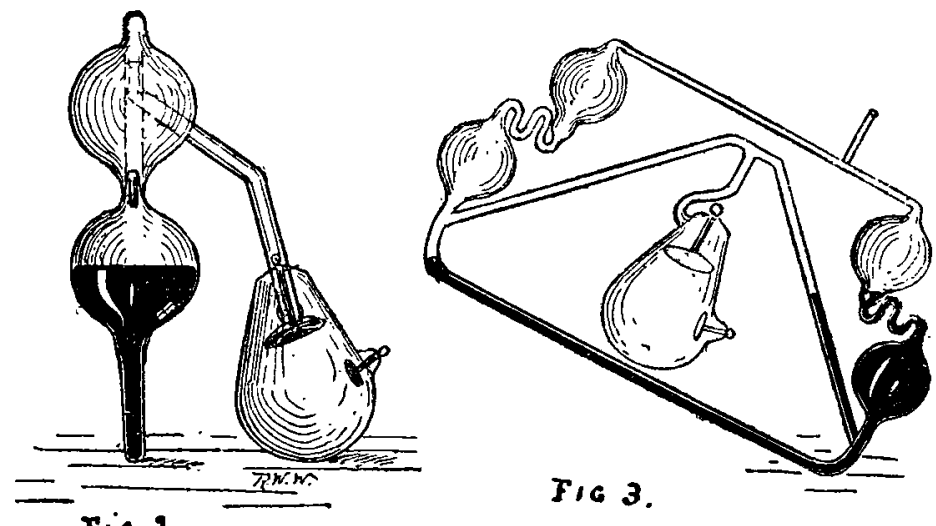

Tis 2.

air-bubble, compressed into the trap by each stroke, is driven entirely around the bend and into the reservoir $B$. If for any reason the pump requires to be subsequently opened, it must be placed in the inclined position and a file scratch made on the tube $P$. A bit of red-hot glass pressed against the scratch will cause a crack through which the air will slowly enter. If the tube be broken open suddenly, the mercury will be forced over into the discharge-tube. I con- 
structed my apparatus with the Röntgen tube projecting to one side, as shown in the side view, fig. 2. 'This makes a support for the pump so that it will stand alone. A pump of this description in connexion with an ordinary "Dark-space" tube makes a very convenient piece of lecture-room apparatus for showing the character of the discharge at different pressures. By tipping the pump far enough the upper trap can be emptied, and the air stored in B returned to the dischargetube again, showing the phenomena at higher pressure.

Owing to the absence of rubber connexions and stopcocks, the mercury remains always clean and there is no leakage.

I am now constructing a pump on this principle on a large scale for general laboratory use in which the rocking motion is to be effected by water-pressure, which, if found serviceable, will be deseribed in a subsequent paper. The chief objection, of course, is that the entire pump is in motion, which makes its connexion with a stationary receiver somewhat difficult. This can perhaps be done by bringing the exhaust-tube into coincidence with the axis of rotation, and using a rubber tube surrounded with mercury as a joint.

The snuall pump can be ordered with or without the Röntgen tube from Herr Glasbläser R. Burger, Chausseestr. 2 e, Berlin, Germany.

Berlin: Physikalische Institut.

XL. Intelligence and Miscellaneous Articles.

NOTES OF OBSERVATIONS ON THE RÖNTGEN RAYS.

BY HENRY A. ROWLAND, N. R. CARMICHAEL, AND L. J. BRIGGS.

THE discovery of Hertz some years since that the cathode rays penetrated some opaque bodies like aluninium, has opened up a wonderful field of research, which has now culminated in the discovery by Röntgen of still other rays having even more remarkable properties. We have confirmed, in many respects, the researches of the latter on these rays and have repeated his experiments in photographing through wood, aluminium, cardboard, hard rubber, and even the larger part of a millimetre of sheet copper.

Some of these photographs have been indistinct, indicating a source of these rays of considerable extent, while others have been so sharp and clear cut that the shadow of a coin at the distance of $2^{\mathrm{em}}$ from the photographic plate bas no penumbra whatever, but appears perfectly sharp even with a low-power microscope.

So far as yet observed the rays proceed in straight lines, and all efforts to deflect them by a strong magnet either within or without the tube have failed. Likewise prisms of wood and vulcanite have Phil. Mag. S. 5. Vol. 41. No. 251. April 1896. 2D 